\title{
Flexibility analysis and design of heat exchanger network for syngas-to-methanol process
}

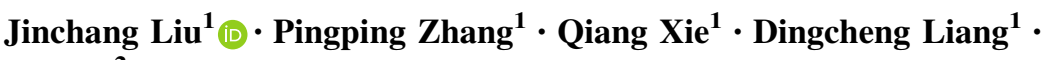 \\ Lei $\mathrm{Bai}^{2}$
}

Received: 29 September 2020/Revised: 6 January 2021 / Accepted: 25 March 2021 / Published online: 16 April 2021

(C) The Author(s) 2021

\begin{abstract}
The heat exchanger network (HEN) in a syngas-to-methanol process was designed and optimized based on pinch technology under stable operating conditions to balance the energy consumption and economic gain. In actual industrial processes, fluctuations in production inevitably affect the stable operation of HENs. A flexibility analysis of the HEN was carried out to minimize such disturbances using the downstream paths method. The results show that two-third of the downstream paths cannot meet flexibility requirements, indicating that the HEN does not have enough flexibility to accommodate the disturbances in actual production. A flexible HEN was then designed with the method of dividing and subsequent merging of streams, which led to $13.89 \%$ and $20.82 \%$ reductions in energy consumption and total cost, respectively. Owing to the sufficient area margin and additional alternative heat exchangers, the flexible HEN was able to resist interference and maintain production stability and safety, with the total cost increasing by just $4.08 \%$.
\end{abstract}

Keywords Heat exchanger network $\cdot$ Syngas-to-methanol $\cdot$ Pinch technology $\cdot$ Flexibility analysis $\cdot$ Design $\cdot$ Optimization

\section{List of symbols}

$\Delta T_{\min }$

Minimum

heat transfer

difference

$Q_{\mathrm{H}, \min }$

$Q_{\mathrm{C}, \min }$

$\theta$

$z$

Minimum hot utility

Minimum cold utility

Disturbed variable

Controlled variable

Supplementary Information The online version contains supplementary material available at https://doi.org/10.1007/s40789021-00426-4.

Jinchang Liu

liujinchang@cumtb.edu.cn

$\triangle$ Lei Bai

lebai@mix.wvu.edu

1 School of Chemical and Environmental Engineering, China University of Mining and Technology (Beijing), D11 Xueyuan Road, Haidian District, Beijing 100083, China

2 Department of Chemical and Biomedical Engineering, West Virginia University, 395 Evansdale Drive, PO Box 6102, Morgantown, WV 26506-6102, USA

$(i, j)$ and Elements of a node adjacency matrix

$(p, q)$

$\mathrm{S} \quad$ A set of nodes

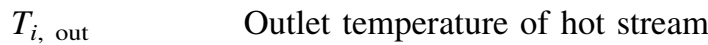

$T_{i, \max } \quad$ Inlet temperature of hot stream

$T_{j}$, out $\quad$ Outlet temperature of cold stream

$T_{j, \text { max }} \quad$ Inlet temperature of cold stream

$\theta_{\mathrm{N}} \quad$ Reference value

$\Delta \theta^{+}$and $\Delta \theta^{-} \quad$ Expected deviations

\section{Introduction}

Methanol is one of the most important raw materials in the chemical industry for producing formaldehyde, acetic acid, methyl formate, etc. It has also been used as fuel for methanol automobiles ( $\mathrm{Li}$ et al. 2010; Riaz et al. 2013). Along with the rapid development of the coal and chemical industry in recent years, methanol has played an important role in comprehensive coal utilization processes, including 
coal-to-olefins, coal-to-dimethyl ether, and other coal-tochemical conversions (Galadima and Muraza 2015; Gao et al. 2018). Generally, syngas from coal gasification technology is used to synthesize methanol via catalytic processes. Coal-based syngas-to-methanol technology has been the main route for methanol production, especially in China, because of its unique situation in terms of energy resources, that is, it is rich in coal but poor in oil and natural gas ( $\mathrm{Li}$ et al. 2010).

Several studies have focused on the energy utilization efficiency of the coal-based syngas-to-methanol process because of its high energy consumption (Riaz et al. 2013; Bessa et al. 2012; Cui et al. 2017; Rashid et al. 2011; Sun et al. 2012). For example, the entire coal-to-olefins process consists of six subprocesses, including coal mining, transportation, coal-to-methanol (CTM), methanol-to-olefins, product delivery, and carbon capture and storage (CCS) (Gao et al. 2018). The CTM subprocess consumes the most energy, accounting for $71.04 \%$ of the total energy consumption, which is five times greater than that of the CCS subprocess (13.81\%) (Gao et al. 2018). Extensive efforts have been made to develop energy-saving strategies for the CTM process; among these, crude methanol purification technology has attracted much attention. A five-column heat integrated methanol distillation scheme was proposed by adding a medium-pressure column, which significantly reduced the total energy loss by $21.5 \%$ compared with the previous four-column purification scheme (Sun et al. 2012; Chien et al. 2005). A hybrid methanol purification process was developed to improve energy efficiency, which combined heat pump distillation and double-effect thermal integration by designing an intermediate heater to shunt the heat load of the reboiler (Bessa et al. 2012; Douglas and Hoadley 2006). Although these strategies can reduce energy consumption of certain subprocesses in the syngasto-methanol process, other energy-saving strategies that can improve the energy efficiency of the overall process should also be considered.

The study of heat exchanger networks (HENs) could lead to a comprehensive heat exchange strategy for the entire syngas-to-methanol process by considering energy utilization, energy efficiency, operation cost, equipment cost, etc. Energy consumption can be reduced by using an optimized heat exchange strategy according to the results of global HEN analysis (Kang and Liu 2019). Currently, the optimal HEN can be calculated via pinch technology, which was developed for analyzing potential energy savings and economic gains (Rashid et al. 2011). Previous studies (Kang and Liu 2019; Payet et al. 2018) have reported that the energy consumption and operating cost of the syngas-to-methanol process can be reduced by restructuring the HEN according to the results of pinch analysis. However, the optimization of the HEN has always been carried out under stable heat transfer operating conditions, while ignoring some inevitable uncertainties arising from various external and internal factors (e.g., feed status, product output, heat transfer coefficients, fouling, etc.). To make the optimal HEN from pinch analysis more precise and practical, a flexibility analysis was introduced by considering these uncertain factors under real operating conditions (Payet et al. 2018; Zhu et al. 1996). However, few studies have focused on the flexibility analysis of the HEN for methanol production.

In this work, the syngas-to-methanol process was first simulated with an optimized HEN by pinch technology under the assumption of stable operating conditions. Then, a flexibility analysis of the optimized HEN was conducted using the heuristic method. The "downstream paths" approach was used to determine the variables for building a flexible HEN. The flexible HEN was improved to meet actual production requirements with a sufficient area margin and number of heat exchangers. This work proposes a feasible strategy to reduce the energy consumption, equipment costs, and operating costs of the syngas-tomethanol process by performing a flexibility analysis of an optimized HEN.

\section{Methodology and simulation}

\subsection{Pinch technology}

Pinch technology, proposed by Linnhoff and Hindmarsh (1983), is a methodology for minimizing the energy consumption of chemical processes. Pinch technology has been widely used in the design and construction of new HENs as well as in the energy-saving modification of old equipment. The pinch analysis mechanism, based on thermodynamics and computational topology, analyzes the distribution of energy flows and the temperature in a chemical process. The objectives of pinch analysis are to find the heat integration bottleneck, namely "the pinch," and provide a solution to reduce the energy consumed by a given process (Binosi and Papavassiliou 2009; Tan et al. 2014). The Aspen Energy Analyzer software was utilized to compute and optimize the HEN according to pinch technology.

\subsection{Flexible analysis}

Generally, the design and optimization of HENs are based on stable operating conditions. However, uncertain factors affect the stability of HENs in actual production. Uncertain factors (e.g., feed status fluctuation) can cause the operation of the HEN to deviate from the optimal state or even cease altogether. Thus, in the design and optimization of 
the HEN, it is necessary to meet the flexibility requirements under fluctuating operating conditions, instead of simply considering stable operating conditions. The concept of the flexible index was first proposed by Swaney and Grossmann in 1987 to measure the maximum deviation of uncertain factors from stable operating conditions in the feasible region; a strict mathematical model was also established (Swaney and Grossmann 1985). The flexibility analysis includes mathematical programming and heuristic methods (Grossmann and Kravanja 1995; Linnhoff and Kotjabasakis 1986). The mathematical programming method is frequently used to study the feasibility of HENs in a specific disturbed domain under certain constraints, while the heuristic method is mainly applied in the detailed structural analysis of HENs to determine the feasibility in the entire disturbed domain based on the experience in chemical engineering (Grossmann and Kravanja 1995; Linnhoff and Kotjabasakis 1986). The heuristic method is much simpler and more convenient than the mathematical programming method, which is widely used in the field of chemical engineering, particularly in relatively short chemical processes. Moreover, a feasible and precise strategy for HENs can be obtained by the heuristic method, whereas the mathematical programming method is only used to test the feasibility of existing HENs under different disturbance conditions. In the heuristic method, the concept of downstream paths was developed to find a balance between the flexibility and economics of HENs. Downstream paths have been used as a convenient approach for determining the disturbed and controlled variables of HENs during flexibility analysis (Linnhoff and Kotjabasakis 1986). A path is defined as the uninterrupted connection between any two nodes in the grid diagram of a HEN. A downstream path is defined as the directed path that is always in the same direction as the streams through which it passes (Zhu et al. 1996). Thus, the disturbance occurring in the HEN can only affect the controlled variables along with the downstream paths between the disturbed and controlled variables.

\subsection{Process simulation}

The technical route adapted in this study is illustrated in Fig. S1 in Supplementary Material. The process simulation was performed using Aspen Plus V10. The original HEN, traditional optimal HEN, and flexible HEN were designed and optimized using the Aspen Energy Analyzer V10 based on the theories of pinch technology and heuristic methods. The entire syngas-to-methanol process was divided into two parts for the simulation: methanol synthesis and methanol purification, as shown in Fig. 1. The information of all blocks and streams are listed in Table S1 in Supplementary Material. The Lurgi low-pressure methanol synthesis process was adopted to simulate the methanol synthesis process. The synthetic reaction was carried out at $250{ }^{\circ} \mathrm{C}$ and $5 \mathrm{MPa}$ in a Lurgi reactor, modeled by combining the RPLUG and RSTOIC reactor blocks in Aspen Plus. RPLUG and RSTOIC were used to model the two main reactions and six side reactions, respectively. The reaction equations and kinetic parameters are listed in Table S2 in Supplementary Material. The equipment parts in which methanol synthesis and methanol purification processes are performed were connected by stream PCFIN. In the methanol purification process, small quantities of lightweight components (e.g., dimethyl ether and methyl formate) dissolved in crude methanol were removed in the predistillation column (Block PC). Double-effect distillation, which combined a high-pressure column (Block HC) and an atmospheric column (Block CC), was applied to remove impurities, such as water, ethanol, and $n$-butanol. The purity of the obtained methanol product reached $99.98 \mathrm{wt} \%$. The compositions and volume fractions of syngas and crude methanol are listed in Table S3 and S4 in Supplementary Material, respectively.

\section{Design and optimization of HEN}

\subsection{Determination of energy targets}

The datasheet of the process simulation obtained by Aspen Plus was imported directly into the Aspen Energy Analyzer to design the HEN. The temperature and enthalpy of each stream participating in heat exchange are listed in Table 1. Through the computations of the Aspen Energy Analyzer, the total cost index was maintained at a low level when the minimum heat transfer temperature difference $\left(\Delta T_{\min }\right)$ ranged between 4 and $11^{\circ} \mathrm{C}$ (Fig. S2 in Supplementary Material). Here, the value of $\Delta T_{\min }$ was set to $11^{\circ} \mathrm{C}$ because the empirical value of $\Delta T_{\min }$ is generally within the range of $10-20{ }^{\circ} \mathrm{C}$ by considering factors such as utilities and heat exchanger equipment cost, heat exchange media, heat transfer coefficient, and operation flexibility (Kang and Liu 2019). The composite curves and grand composite curves are shown in Fig. S3 and S4 in Supplementary Material, respectively. The pinch-point temperatures of the hot and cold streams were $135{ }^{\circ} \mathrm{C}$ and $124{ }^{\circ} \mathrm{C}$, respectively, from the composite curves (see Fig. S3 in Supplementary Material) when $\Delta T_{\min }$ was set to $11^{\circ} \mathrm{C}$. The minimum hot utility $\left(Q_{\mathrm{H},}, \min \right)$ target was $1.460 \times 10^{8} \mathrm{~kJ} / \mathrm{h}$, while the minimum cold utility $\left(Q_{\mathrm{C}, \min }\right)$ target was $2.396 \times 10^{8} \mathrm{~kJ} / \mathrm{h}$. According to Fig. S4 in Supplementary Material, the average temperature to process the pinch point was confirmed as $129.5{ }^{\circ} \mathrm{C}$ when the corresponding enthalpy was $0 \mathrm{~kJ} / \mathrm{h}$. 


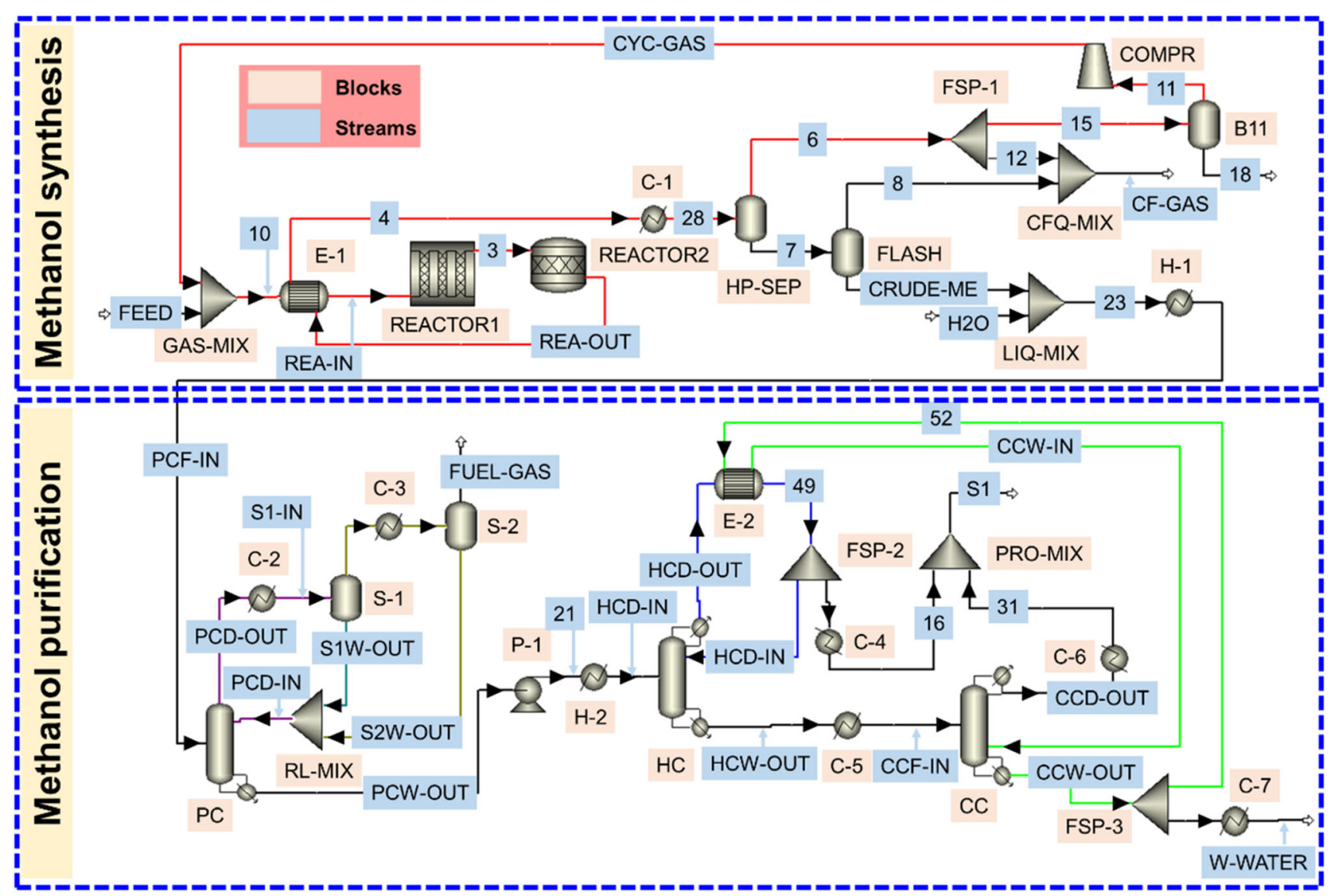

Fig. 1 Simulation flowsheet of syngas-to-methanol

Table 1 Datasheet of streams involving heat exchange

\begin{tabular}{|c|c|c|c|c|}
\hline $\begin{array}{l}\text { Steam } \\
\text { No. }\end{array}$ & Steam name & $T_{\text {in }}\left({ }^{\circ} \mathrm{C}\right)$ & $T_{\text {out }}\left({ }^{\circ} \mathrm{C}\right)$ & Enthalpy $(\mathrm{kJ} / \mathrm{h})$ \\
\hline $\mathrm{H} 1$ & REA-OUT_To_28 & 250.0 & 40.0 & $1.52 \times 10^{8}$ \\
\hline $\mathrm{H} 2$ & HCW-OUT_To_CCF-IN & 129.2 & 80.3 & $5.86 \times 10^{6}$ \\
\hline $\mathrm{H} 3$ & HCD-OUT_To_49 & 122.3 & 121.8 & $1.46 \times 10^{8}$ \\
\hline $\mathrm{H} 4$ & 24_To_16 & 122.3 & 40.0 & $5.58 \times 10^{6}$ \\
\hline H5 & 27_To_W-WATWER & 107.3 & 40.0 & $1.80 \times 10^{6}$ \\
\hline H6 & To Condenser@CC_TO_CCD-OUTDuplicate & 74.9 & 71.0 & $1.46 \times 10^{8}$ \\
\hline $\mathrm{H} 7$ & PCD-OUT_To_S1-IN & 73.3 & 64.0 & $1.55 \times 10^{7}$ \\
\hline $\mathrm{H} 8$ & CCD-OUT_To_31 & 71.0 & 40.0 & $2.22 \times 10^{6}$ \\
\hline H9 & S1D-OUT_To_S2-IN & 64.0 & 40.0 & $1.71 \times 10^{6}$ \\
\hline $\mathrm{C} 1$ & 10_To_REA-IN & 124.0 & 230.0 & $5.51 \times 10^{7}$ \\
\hline $\mathrm{C} 2$ & To Reboiler@HC_TO_HCW-OUTDuplicate & 126.9 & 129.2 & $1.46 \times 10^{8}$ \\
\hline $\mathrm{C} 3$ & 21_To_HCF-IN & 81.7 & 127.0 & $8.76 \times 10^{6}$ \\
\hline $\mathrm{C} 4$ & 52_To_CCW-IN & 107.3 & 110.9 & $1.46 \times 10^{8}$ \\
\hline $\mathrm{C} 5$ & To Reboiler@PC_TO_PCW-OUT & 81.1 & 81.7 & $1.85 \times 10^{7}$ \\
\hline C6 & 23_To_PCF-IN & 20.4 & 75.0 & $8.65 \times 10^{6}$ \\
\hline
\end{tabular}




\subsection{Original HEN and traditional optimal HEN}

The original HEN of the syngas-to-methanol process generated by the Aspen Energy Analyzer is shown in Fig. S5 in Supplementary Material. The original HEN includes two process-process heat exchangers (white matches), nine coolers (blue matches), and five heaters (red matches). The original HEN was optimized under the assumption of stable operating conditions to obtain the traditional optimal HEN, as shown in Fig. S6 in Supplementary Material. The optimized HEN contains seven process-process heat exchangers, seven coolers, and two heaters.

\subsection{Flexible HEN}

\subsubsection{Flexibility analysis of HEN}

The disturbed and controlled variables of the HEN in the syngas-to-methanol process were determined using the downstream paths approach. Disturbed variables fluctuate owing to changes in the external environment, equipment operation, production load, etc. In the actual production process, the temperatures of several streams were determined as the disturbed variables, i.e., the feedstock stream and outlet stream of the reactor; the mixing stream of crude methanol with water, and the bottom outlet stream of the predistillation column (Rashid et al. 2011). Here, $\theta$ is denoted as the disturbed variables; $\theta_{1}$ is the temperature of the feedstock stream $\mathrm{C} 1 ; \theta_{2}$ is the temperature of the outlet stream (H1) of the reactor; $\theta_{3}$ is the temperature of the mixing stream (C6) of crude methanol with water, and $\theta_{4}$ is the temperature of the bottom outlet stream (C3) of the predistillation column. Controlled variables are defined as those that are strictly manipulated to maintain stability and ensure safety in the actual production process. In the syngas-to-methanol system, the inlet stream temperature of the reactor must be strictly controlled to ensure the stability of the production load and feedstock conversion rate. In addition, control of the feed stream temperature of the pressured column and the atmospheric column is required owing to the sensitive inlet temperature requirements for double-effect distillation. Therefore, the temperatures of (1) the reactor inlet stream and (2) the feed streams of the pressured column and atmospheric column were set as the controlled variables. Here, $z$ is the controlled variable; $z_{1}$ is the temperature of the reactor inlet stream (C1); $z_{2}$ is the temperature of the feed stream (C3) of the pressured column, and $z_{3}$ is the temperature of the feed stream $(\mathrm{H} 2)$ of the atmospheric column. Figure 2 shows the positions of the disturbed and controlled variables in the grid diagram of the traditional optimal HEN.

A method for determining downstream paths was developed using the node adjacency matrix that represents the connection of units along the direction of the HEN streams (Zhu et al. 1996). Units, splitting, and mixing points as well as various variables in the HEN were all

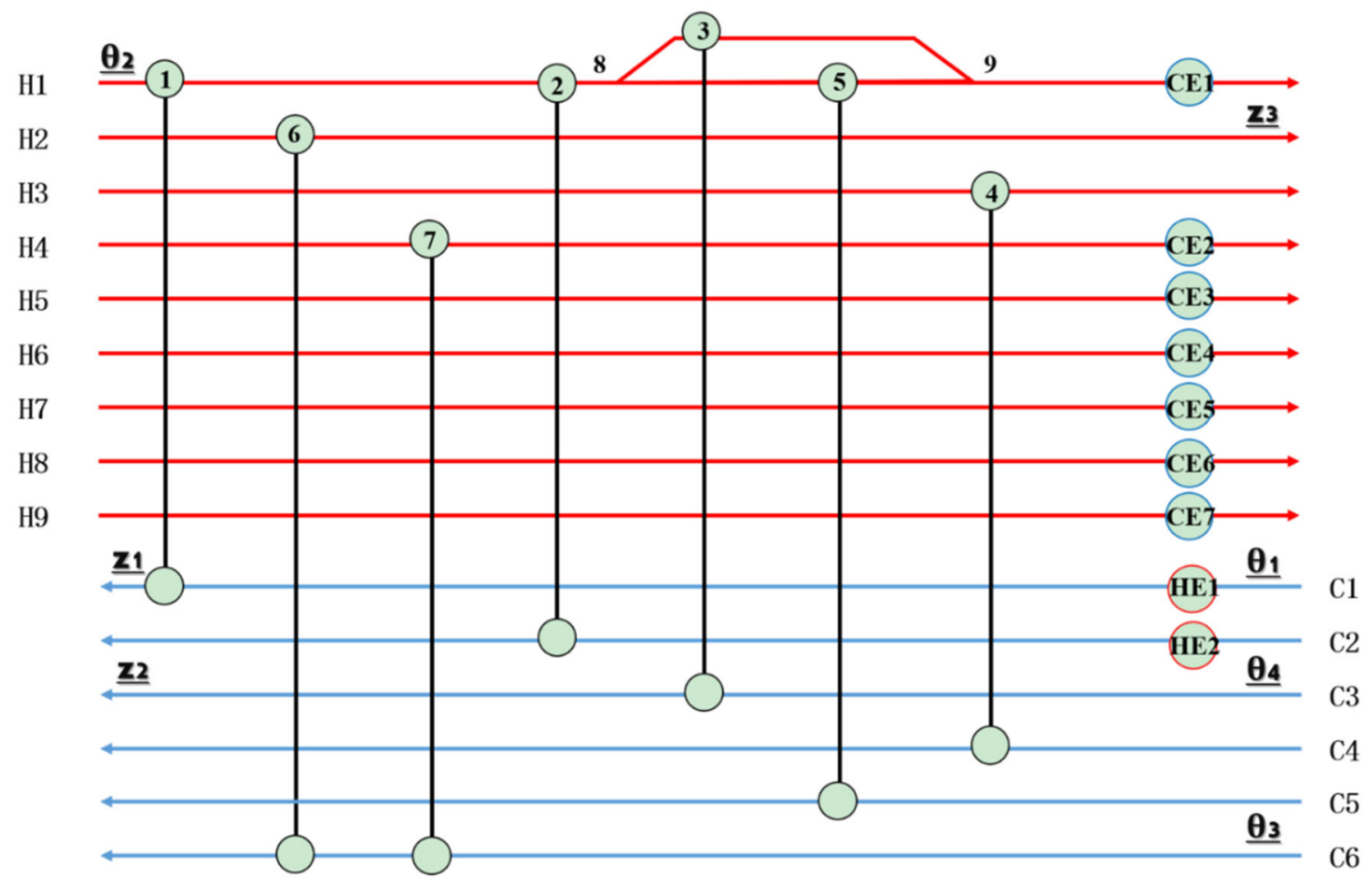

Fig. 2 Disturbed variables and controlled variables in the grid diagram of traditional optimal HEN 
Flexibility analysis and design of heat exchanger network for syngas-to-methanol process

1473

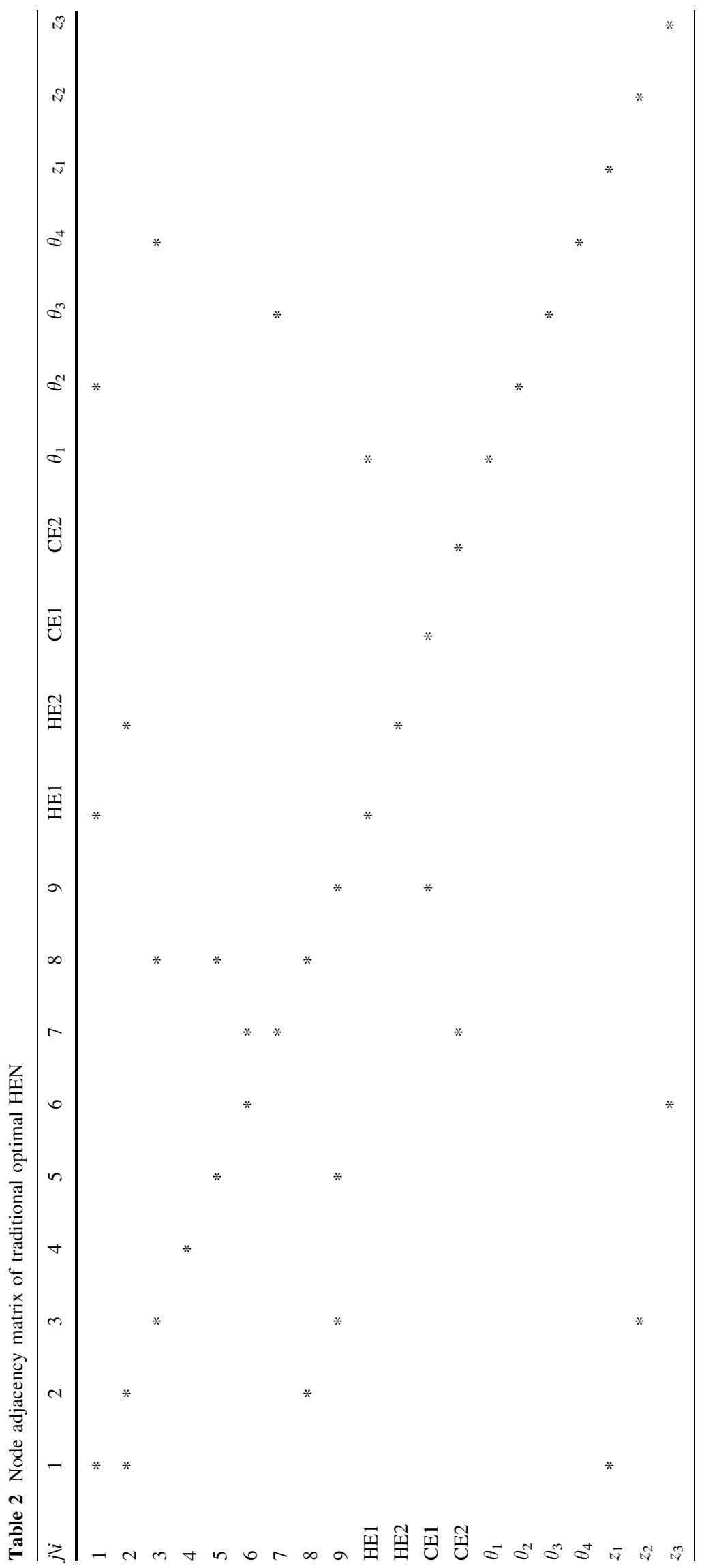

算 Springer 
Table 3 Downstream paths between disturbed and controlled variables

\begin{tabular}{llll}
\hline Number of downstream paths & Initial node & Process nodes & Final node \\
\hline 1 & $\theta_{1}$ & HE1, 1 & $z_{1}$ \\
2 & $\theta_{1}$ & HE1, 1, 2, 8, 3 & $z_{2}$ \\
3 & $\theta_{2}$ & 1 & $z_{1}$ \\
4 & $\theta_{2}$ & $1,2,8,3$ & $z_{2}$ \\
5 & $\theta_{3}$ & 7,6 & $z_{3}$ \\
6 & $\theta_{4}$ & 3 & $z_{2}$ \\
\hline
\end{tabular}

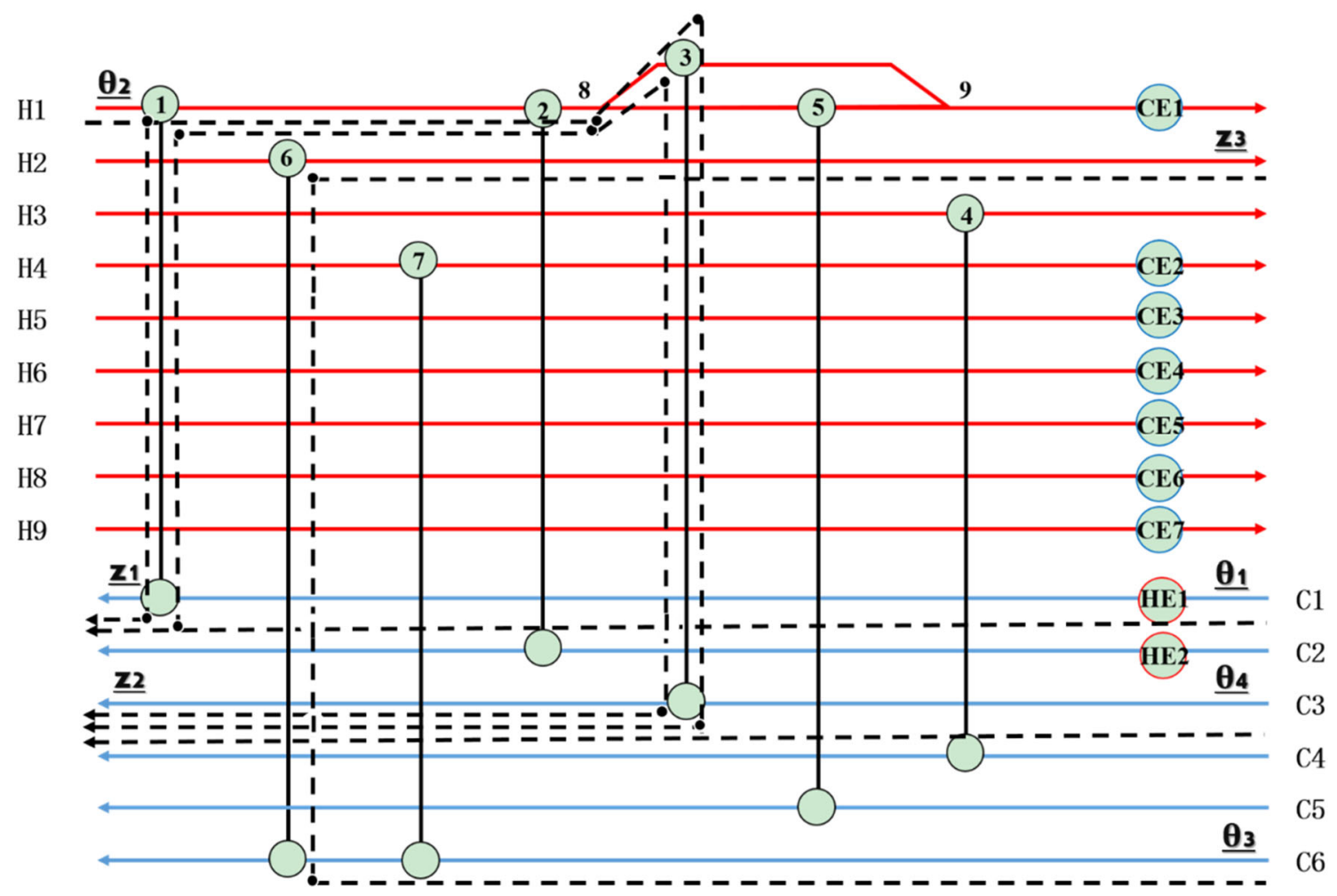

Fig. 3 Downstream paths between disturbed variables and controlled variables

Table 4 Reference values of disturbed variables and their expected deviation

\begin{tabular}{lccc}
\hline Disturbance variable & $\theta_{\mathrm{N}}\left({ }^{\circ} \mathrm{C}\right)$ & $\Delta \theta^{+}\left({ }^{\circ} \mathrm{C}\right)$ & $\Delta \theta^{-}\left({ }^{\circ} \mathrm{C}\right)$ \\
\hline$\theta_{1}=T_{\mathrm{C} 1}$ & 124.0 & 10 & 10 \\
$\theta_{2}=T_{\mathrm{H} 1}$ & 250.0 & 10 & 10 \\
$\theta_{3}=T_{\mathrm{C} 6}$ & 20.4 & 10 & 0 \\
$\theta_{4}=T_{\mathrm{C} 3}$ & 82.7 & 5 & 5 \\
\hline
\end{tabular}

considered as nodes. In the adjacency matrix, both the row and column headings represent the abovementioned nodes. The $(i, j)$ th entry of the matrix is filled with "*" if node $j$ can directly reach node $i$ in the direction of the stream; otherwise, it is left blank. The nodes of the coolers or heaters in the matrix, which were not adjacent to other nodes, were deleted for the sake of simplicity (Table 2). In this case, the determination of the downstream paths between the disturbed and controlled variables can be transformed into the determination of the downstream paths between the two nodes, $i$ and $j$. The detailed approach for finding the downstream path is described as follows. (Step I) $\theta_{i}(i=1,2, \ldots, I)$ and $z_{j}(j=1,2, \ldots, J)$ represent the number of disturbed and controlled variables of the HEN, respectively. (Step II) $S$ is defined as a set of nodes, and the serial number of these nodes should start from $i=1$. (Step III) For the last node $p$ in $S$, the node $q$ that can be directly reached from node $p$ along with the direction of the stream must be confirmed, i.e., if the $(p, q)$ th entry is filled with "*" in the node adjacency matrix, then add $q$ to 
Table 5 Datasheet of process streams obtained by the dividing principle

\begin{tabular}{|c|c|c|c|c|}
\hline $\begin{array}{l}\text { New } \\
\text { No. }\end{array}$ & $\begin{array}{l}\text { Old } \\
\text { No. }\end{array}$ & $T_{\text {in }}\left({ }^{\circ} \mathrm{C}\right)$ & $T_{\text {out }}\left({ }^{\circ} \mathrm{C}\right)$ & $q(\mathrm{~kJ} / \mathrm{h})$ \\
\hline h1 & $\mathrm{H} 1^{\mathrm{g}}$ & 260 & 240 & $9.72 \times 10^{6}$ \\
\hline h2 & $\mathrm{H} 1^{\mathrm{d}}$ & 240 & 40 & $1.48 \times 10^{8}$ \\
\hline h3 & $\mathrm{H} 2$ & 129.2 & 80.3 & $5.86 \times 10^{6}$ \\
\hline $\mathrm{h} 4$ & $\mathrm{H} 3$ & 122.3 & 121.8 & $1.46 \times 10^{8}$ \\
\hline h5 & $\mathrm{H} 4$ & 122.3 & 40 & $5.58 \times 10^{6}$ \\
\hline h6 & H5 & 107.3 & 40 & $1.80 \times 10^{6}$ \\
\hline h7 & H6 & 74.9 & 71 & $1.46 \times 10^{8}$ \\
\hline h8 & H7 & 73.3 & 64 & $1.55 \times 10^{7}$ \\
\hline h9 & $\mathrm{H} 8$ & 71 & 40 & $2.22 \times 10^{6}$ \\
\hline h10 & $\mathrm{H} 9$ & 64 & 40 & $1.71 \times 10^{6}$ \\
\hline $\mathrm{c} 1$ & $\mathrm{C} 1^{\mathrm{g}}$ & 134 & 230 & $4.99 \times 10^{7}$ \\
\hline $\mathrm{c} 2$ & $\mathrm{C} 1^{\mathrm{d}}$ & 114 & 134 & $1.02 \times 10^{7}$ \\
\hline c3 & $\mathrm{C} 2$ & 126.8 & 129.8 & $1.46 \times 10^{8}$ \\
\hline c4 & $C 3^{\mathrm{g}}$ & 86.7 & 127 & $7.85 \times 10^{6}$ \\
\hline $\mathrm{c} 5$ & $C 3^{\mathrm{d}}$ & 76.7 & 86.7 & $1.76 \times 10^{6}$ \\
\hline c6 & $\mathrm{C} 4$ & 107.3 & 110.9 & $1.46 \times 10^{8}$ \\
\hline c7 & $\mathrm{C} 5$ & 81.1 & 81.7 & $1.85 \times 10^{7}$ \\
\hline c8 & $C 6^{\mathrm{g}}$ & 30.4 & 75 & $7.13 \times 10^{6}$ \\
\hline c9 & $C 6^{\mathrm{d}}$ & 20.4 & 30.4 & $1.52 \times 10^{6}$ \\
\hline
\end{tabular}

set $S$. Step III will stop if $S$ contains all the nodes of the HEN, or the $(p, q)$ th entry is blank in the node adjacency matrix for each $q$. If node $z_{j}$ is included in set $S$, then there is a downstream path between node $\theta_{i}$ and node $z_{j}$; otherwise, let $i=i+1$ and go back to Step II until $i>I$. For the traditional optimal HEN, the results of identifying the downstream paths between all disturbed and controlled variables are given in Table 3; each downstream path is plotted in Fig. 3.

\subsubsection{Flexibility design of HEN}

For an HEN with temperature fluctuations, heat recovery reaches a maximum when the inlet temperatures of all hot streams take the upper limit of fluctuations, while the inlet temperatures of all cold streams take the lower limit. With this assumption, it is possible to obtain the maximum design margin, and subsequently meet the requirements for various operating conditions in actual production. The stream-dividing principle was used to design a flexible HEN (Zhihong and Ben 1999). The details are as follows. (i) For hot stream $i$, its outlet temperature is denoted as $T_{i \text {, out }}$, while the inlet temperature is in the range of $T_{i, \mathrm{~min}^{-}}$ $T_{i \text {, max }}$. Hot stream $i$ can be divided into the high-temperature stream and low-temperature stream. In the hightemperature stream, the inlet and outlet temperatures are $T_{i, \max }$ and $T_{i, \min }$, respectively. In the low-temperature stream, the inlet and outlet temperatures are $T_{i}$, min and $T_{i}$, out, respectively. (ii) Similarly, for cold stream $j$, its outlet temperature is referred to as $T_{j \text {, out }}$, and the inlet temperature is in the range of $T_{j, \min }-T_{j, \max }$. Cold stream $j$ can be divided into the high-temperature stream and low-

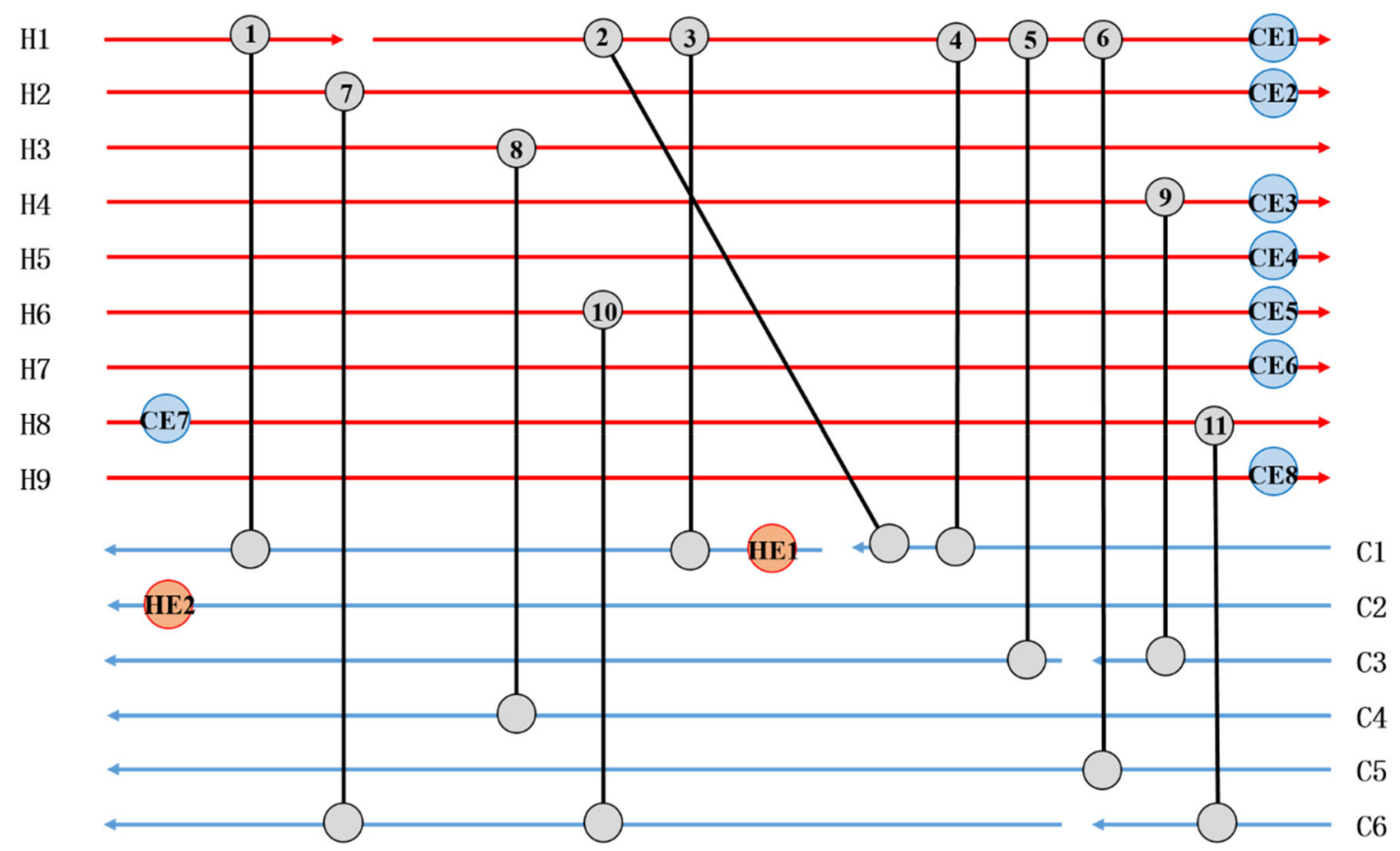

Fig. 4 Grid diagram of flexible HEN with merging the segmented streams 


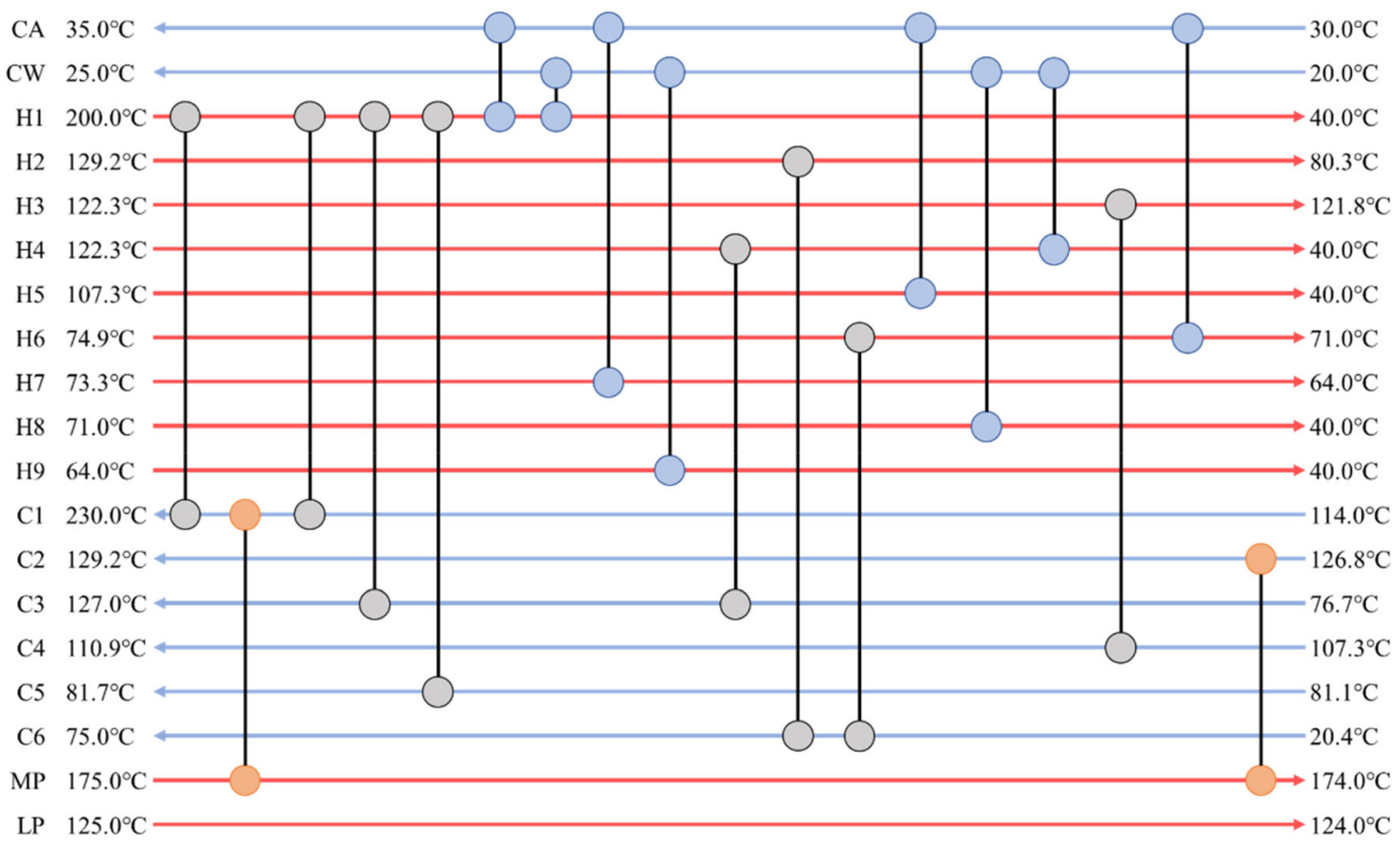

Fig. 5 Final flexible HEN

temperature stream. In the high-temperature stream, the inlet and outlet temperatures are $T_{i, \max }$ and $T_{j}$, respectively. In the low-temperature stream, the inlet temperature is $T_{i, \min }$, and the outlet temperature is $T_{j \text {, max }}$. The fluctuation ranges of the disturbed variables were determined according to the actual production, as listed in Table 4 (Zamora and Grossmann 1997). $\theta_{\mathrm{N}}$ was set as the reference value. $\Delta \theta^{+}$and $\Delta \theta^{-}$are the expected deviations.

The process streams with disturbed variables were divided according to the dividing principle; the data are listed in Table 4. The segmented streams were treated as independent streams. Then, the data of all streams shown in Table 5 were imported into the Aspen Energy Analyzer to design the flexible HEN. The final flexible HEN was obtained after merging the segmented streams and relaxing the energy load. The detailed procedure is as follows.

(i) The segmented process streams were first merged to obtain the network structure shown in Fig. 4. (ii) Then, the load loops were relaxed along the direction of the downstream paths of the merged streams. (iii) Finally, the flexible HEN was obtained by adjusting the parameters of each heat exchanger, as shown in Fig. 5. The merging of segmented streams was conducted based on the design results under the condition of maximum heat recovery. Energy relaxation can reduce the number of heat exchangers in the entire process. Consequently, the final flexible HEN is optimized.

\section{Results and discussion}

From Fig. S5 in Supplementary Material, the strategy of the original HEN employed the excessive number of 16 utilities, which can be attributed to two reasons. One is the

Table 6 Parameters of original HEN and flexible HEN

\begin{tabular}{llll}
\hline Parameter & Original HEN & Flexible HEN & Reduction $(\%)$ \\
\hline Heating utilities $(\mathrm{kJ} / \mathrm{h})$ & $1.819 \times 10^{8}$ & $1.508 \times 10^{8}$ & 17.12 \\
Cooling utilities $(\mathrm{kJ} / \mathrm{h})$ & $2.756 \times 10^{8}$ & $2.432 \times 10^{8}$ & 11.76 \\
Number of shells & 55 & 37 & 32.73 \\
Total area $\left(\mathrm{m}^{2}\right)$ & $2.066 \times 10^{4}$ & $1.191 \times 10^{4}$ & 42.35 \\
Capital cost $($ Cost $)$ & $5.099 \times 10^{6}$ & $3.080 \times 10^{6}$ & 39.60 \\
Operating cost $($ Cost/s) & 0.1053 & 0.0931 & 11.53 \\
Total cost $($ Cost/s) & 0.1573 & 0.1246 & 20.82 \\
\hline
\end{tabular}


Table 7 Parameters of traditional optimal HEN and flexible HEN

\begin{tabular}{lllr}
\hline Parameter & Regular optimized HEN & Flexible HEN & Reduction $(\%)$ \\
\hline Heating utilities $(\mathrm{kJ} / \mathrm{h})$ & $1.468 \times 10^{8}$ & $1.508 \times 10^{8}$ & -2.72 \\
Cooling utilities $(\mathrm{kJ} / \mathrm{h})$ & $2.405 \times 10^{8}$ & $2.432 \times 10^{8}$ & -1.13 \\
Number of shells & 32 & 37 & -15.63 \\
Total area $\left(\mathrm{m}^{2}\right)$ & 9209 & $1.191 \times 10^{4}$ & -29.35 \\
Capital cost $($ Cost $)$ & $2.445 \times 10^{6}$ & $3.080 \times 10^{6}$ & -25.97 \\
Operating cost $($ Cost/s) & 0.0947 & 0.0931 & 1.69 \\
Total cost $($ Cost/s) & 0.1197 & 0.1246 & -4.08 \\
\hline
\end{tabular}

situation in which the cooler crosses two pinch points and the heater crosses the process pinch point, which violates the rule that prohibits a cross-pinch. The other is the presence of three heaters below the pinch point and a cooler above the pinch point, which violates another rule of pinch technology: no heating utility below the pinch point and no cooling utility above the pinch point. It can be concluded that the original HEN contains massive energy that is expected to be recycled. Compared with the original HEN scenario, the traditional optimal HEN significantly improves the heat recovery capacity of the system; the number of heat exchangers is also significantly reduced. Although two process-process heat exchangers cross the pinch point, there is no cooling and heating utility above and below the pinch point, respectively (Fig. S6 in Supplementary Material). In the flexible HEN (Fig. 4), a total of six downstream paths were obtained. The results of the flexibility analysis can be summarized as follows. (i) For downstream paths 1 and 2 with the disturbance variable $\theta_{1}$ as the initial node, it is possible to stop $\theta_{1}$ from affecting the controlled variables $z_{1}$ and $z_{2}$ by adjusting the usage of the heating utility because these two paths pass through node HE1. (ii) For downstream paths 3 and 6, there is only one node of a heat exchanger between the disturbance and control variables, with the former having a direct effect on the latter. Some differences between paths 3 and 6 were observed. Both variables on downstream path 3 were located in different streams. In contrast, the variables on downstream path 6 were in the same stream. (iii) For downstream paths 4 and 5, there are many nodes on each but no utilities node; hence, the fluctuation of the disturbance variable will be transferred to the controlled variable along the downstream path direction. In summary, the controlled variables will be affected as long as the disturbance variables of downstream paths 3-6 fluctuate. Thus, it is difficult for this regular optimized HEN to meet the flexibility requirements in a practical scenario.

Table 6 shows the comparison of major parameters of the original HEN and flexible HEN. The total energy consumption of the flexible HEN decreased by $13.89 \%$ compared with that of the original HEN, indicating a high energy recycling efficiency. The capital cost, operating cost, and total cost in the flexible HEN scenario decreased by $39.60 \%, 11.53 \%$, and $20.82 \%$, respectively.

Table 7 shows a comparison of the major parameters of the traditional optimal HEN and flexible HEN. The cooling and heating utilities in the flexible HEN scenario increased slightly at increments of $2.72 \%$ and $1.13 \%$, respectively, compared with the regular optimized HEN. The number and total area of the heat exchangers increased by $15.63 \%$ and $29.35 \%$, respectively. This illustrates that the essence of the HEN flexibility design in our work is to increase the area margin and appropriately set up alternative heat exchangers. However, the operating cost in the flexible HEN strategy decreased by $1.69 \%$, implying that increasing the HEN flexibility can reduce the frequency and difficulty of operations. The total cost slightly increased $(4.08 \%)$. In the long term, the extended lifespan of heat exchangers will offset the partial increase in capital costs stemming from the additional heat exchangers and area margin.

\section{Conclusions}

In this study, the overall HEN of a syngas-to-methanol process was designed and optimized based on pinch technology under stable operating conditions. Flexibility analysis of the traditional optimal HEN was implemented using the downstream paths method. Six downstream paths between the disturbance variables and control variables were determined by the modified procedure with the node adjacency matrix. The results show that two-thirds of the downstream paths cannot meet flexibility requirements, indicating that the optimized design of the HEN under stable operating conditions is not flexible enough to resist disturbances in actual production. The flexible HEN was realized under the condition of maximum heat recovery by dividing and subsequent merging of streams. Although the total cost of the flexible HEN is $4.08 \%$ higher than that of 
the traditional optimal HEN, the flexible HEN has a sufficient area margin and extra alternative heat exchangers to avoid production disturbances and maintain its stability and safety.

Acknowledgements This work is financially supported by "the Fundamental Research Funds for the Central Universities" (2020XJHH01) and the Yueqi Distinguished Scholar Project of China University of Mining and Technology (Beijing) (2020JCB02).

Authors' contributions JL: Conceptualization, Methodology, Formal analysis, Experiment, Writing-Review \& Editing; PZ: Writing-Original Draft; QX: Writing — Review \& Editing, Supervision; DL: Writing-Review \& Editing; LB: Formal analysis, WritingReview \& Editing.

\section{Declarations}

Conflict of interest The authors declare that they have no known competing financial interests or personal relationships that could have appeared to influence the work reported in this paper.

Open Access This article is licensed under a Creative Commons Attribution 4.0 International License, which permits use, sharing, adaptation, distribution and reproduction in any medium or format, as long as you give appropriate credit to the original author(s) and the source, provide a link to the Creative Commons licence, and indicate if changes were made. The images or other third party material in this article are included in the article's Creative Commons licence, unless indicated otherwise in a credit line to the material. If material is not included in the article's Creative Commons licence and your intended use is not permitted by statutory regulation or exceeds the permitted use, you will need to obtain permission directly from the copyright holder. To view a copy of this licence, visit http://creativecommons. org/licenses/by/4.0/

\section{References}

Bessa LCBA, Batista FRM, Meirelles AJA (2012) Double-effect integration of multicomponent alcoholic distillation columns. Energy 45:603-612. https://doi.org/10.1016/j.energy.2012.07. 038

Binosi D, Papavassiliou J (2009) Pinch technique: theory and applications. Phys Rep 479:1-152. https://doi.org/10.1016/j. physrep.2009.05.001

Chien IL, Teng Y-P, Huang H-P, Tang YT (2005) Design and control of an ethyl acetate process: coupled $\mathrm{r}$ eactor/column configuration. J Process Control 15:435-449. https://doi.org/10.1016/j. jprocont.2004.07.003

Cui C, Sun J, Li X (2017) A hybrid design combining double-effect thermal integration and heat pump to the methanol distillation process for improving energy efficiency. Chem Eng Process 119:81-92. https://doi.org/10.1016/j.cep.2017.06.003

Douglas AP, Hoadley AFA (2006) A process integration approach to the design of the two- and three-column methanol distillation schemes. Appl Therm Eng 26:338-349. https://doi.org/10.1016/ j.applthermaleng.2005.07.001
Galadima A, Muraza O (2015) From synthesis gas production to methanol synthesis and potential upgrade to gasoline range hydrocarbons: a review. J Nat Gas Sci Eng 25:303-316. https:// doi.org/10.1016/j.jngse.2015.05.012

Gao D, Qiu X, Zhang Y, Liu P (2018) Life cycle analysis of coal based methanol-to-olefins processes in China. Comput Chem Eng 109:112-118. https://doi.org/10.1016/j.compchemeng.2017. 11.001

Grossmann IE, Kravanja Z (1995) Mixed-integer nonlinear programming techniques for process systems engineering. Comput Chem Eng 19:189-204. https://doi.org/10.1016/0098-1354(95)00072A

Kang L, Liu Y (2019) Synthesis of flexible heat exchanger networks: a review. Chin J Chem Eng 27:1485-1497. https://doi.org/10. 1016/j.cjche.2018.09.015

Li Z, Gao D, Chang L, Liu P, Pistikopoulos EN (2010) Coal-derived methanol for hydrogen vehicles in China: energy, environment, and economic analysis for distributed reforming. Chem Eng Res Des 88:73-80. https://doi.org/10.1016/j.cherd.2009.07.003

Linnhoff B, Hindmarsh E (1983) The pinch design method for heat exchanger networks. Chem Eng Sci 38:745-763. https://doi.org/ 10.1016/0009-2509(83)80185-7

Linnhoff B, Kotjabasakis E (1986) Downstream paths for operable process design. Chem Eng Prog 5:263-281

Payet L, Thery Hétreux R, Hétreux G, Bourgeois F, Floquet P (2018) Flexibility assessment of heat exchanger networks: from a thorough data extraction to robustness evaluation. Chem Eng Res Des 131:571-583. https://doi.org/10.1016/j.cherd.2017.11. 036

Rashid SRA, Ibrahim UK, Alauddin SM (2011) Retrofit design of heat exchanger network (HEN) on synthesis and purification unit of methanol plant. In: 2011 IEEE Colloquium on Humanities, Science and Engineering Research (CHUSER 2011) Dec 5-6 2011, pp 33-36. https://doi.org/10.1109/CHUSER.2011. 6163746

Riaz A, Zahedi G, Klemeš JJ (2013) A review of cleaner production methods for the manufacture of methanol. J Clean Prod 57:19-37. https://doi.org/10.1016/j.jclepro.2013.06.017

Sun J, Wang F, Ma T, Gao H, Wu P, Liu L (2012) Energy and exergy analysis of a five-column methanol distillation scheme. Energy 45:696-703. https://doi.org/10.1016/j.energy.2012.07.022

Swaney RE, Grossmann IE (1985) An index for operational flexibility in chemical process design. Part I Formulation and theory. AIChE J 31:621-630. https://doi.org/10.1002/aic.690310412

Tan YL, Ng DKS, El-Halwagi MM, Foo DCY, Samyudia Y (2014) Floating pinch method for utility targeting in heat exchanger network (HEN). Chem Eng Res Des 92:119-126. https://doi.org/ 10.1016/j.cherd.2013.06.029

Zamora JM, Grossmann IE (1997) A comprehensive global optimization approach for the synthesis of heat exchanger networks with no stream splits. Comput Chem Eng 21:S65-S70. https:// doi.org/10.1016/S0098-1354(97)87480-7

Zhihong L, Ben H (1999) Synthesis of flexible heat exchanger networks with stream no-splitting(I) based on ranges of stream supply temperatures. J Chem Ind Eng 50:317-325. https://doi. org/10.3321/j.issn:0438-1157.1999.03.005

Zhu J, Han Z, Rao M, Chuang KT (1996) Identification of heat load loops and downstream paths in heat exchanger networks. Can J Chem Eng 74:876-882. https://doi.org/10.1002/cjce.5450740609 